\title{
Detachment of the tricuspid valve for ventricular septal defect closure in infants younger than 3 months
}

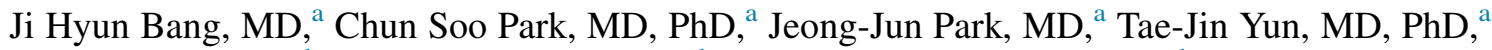 \\ Jae Suk Baek, MD, ${ }^{b}$ Jeong Jin Yu, MD, PhD, ${ }^{b}$ Young-Hwue Kim, MD, PhD, ${ }^{b}$ and Jae-Kon Ko, MD, PhD
}

\section{ABSTRACT}

Objectives: Although several previous studies have reported that a ventricular septal defect (VSD) can be closed safely through the detached tricuspid valve (TV) without impairing TV function, this has not been demonstrated for infants younger than 3 months.

Methods: We enrolled 296 infants younger than 3 months who underwent VSD closure through the right atrium between January 2004 and December 2013. In the study group of 49 patients $(16.6 \%)$, the TV was detached for better exposure of the defect.

Results: The median age and weight were 63.5 days (14-90 days) and $4.4 \mathrm{~kg}$ (2.1-6.7 kg), without intergroup differences. Abnormal chordal attachment of the TV in preoperative echocardiography was associated with detachment of the TV during surgery $(P=.001)$. Cardiopulmonary bypass $(P=.001)$ and aortic crossclamp $(P<.001)$ times were significantly longer in the study group. A permanent pacemaker was required for 2 patients in the control group. Follow-up echocardiography was available for 282 patients at a median of 21 months (1-108 months) after the operation. On final echocardiography, tricuspid regurgitation greater than grade 2 was observed in 1 patient in the study group and residual VSD existed in 4 patients (1 in the study group), without statistical significance.

Conclusions: Detachment of the TV can be used safely for better exposure of the VSD without increased risk of tricuspid regurgitation in infants younger than 3 months. Preoperative echocardiography might be useful for predicting the possibility of detachment of the TV for enhancing exposure of the VSD. (J Thorac Cardiovasc Surg 2016;152:491-6)

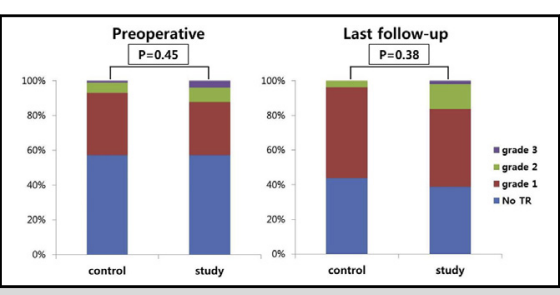

Detachment of the tricuspid valve does not increase regurgitation risk after VSD repair.

\section{Central Message}

Detachment of the tricuspid valve during closure of the ventricular septal defect can be used safely in infants younger than 3 months.

\section{Perspective}

Data regarding patient outcomes after repair of the VSD through an incision in the tricuspid valve in young infants, including neonates, are limited. Because the age at repair tends to decrease and a significant number of babies with VSD associated with complex heart disease require neonatal repair, the outcome of tricuspid valve detachment in young infants, including neonates, merits investigation.

See Editorial Commentary page 496.
Ventricular septal defect (VSD) is among the most common types of congenital heart disease in an isolated form, accounting for more than $20 \%$ of all congenital heart diseases. ${ }^{1}$ In addition, VSD has been associated with many other complex forms of congenital heart disease. Although patient outcomes after surgical closure of the VSD are excellent in terms of mortality and morbidity rates, risks of heart block ${ }^{2}$ or a residual shunt ${ }^{3}$ remain, which

\footnotetext{
From the Divisions of a Pediatric Cardiac Surgery, and ${ }^{\mathrm{b}}$ Pediatric Cardiology, Asan Medical Center, University of Ulsan College of Medicine, Seoul, Korea.

Received for publication Jan 27, 2016; revisions received March 4, 2016; accepted for publication March 22, 2016; available ahead of print May 6, 2016.

Address for reprints: Chun Soo Park, MD, PhD, Division of Pediatric Cardiac Surgery, Asan Medical Center, University of Ulsan College of Medicine, 88, Olympic-ro 43-gil, Songpa-gu, Seoul 05505, Republic of Korea (E-mail: hopang1974@hanmail.net).

$0022-5223 / \$ 36.00$

Copyright (c) 2016 by The American Association for Thoracic Surgery

http://dx.doi.org/10.1016/j.jtcvs.2016.03.067
}

could be attributable to inadequate exposure of the defect. Exposure of the whole margin of the VSD while preserving tricuspid valve (TV) function and the conduction axis is a prerequisite for the successful repair of a VSD.

In cases in which the margin of the VSD is difficult to expose, various types of incisions of the TV have been used for adequate exposure of the VSD without increasing the risk of residual shunt, tricuspid regurgitation (TR), or heart block. ${ }^{4-10}$ Although many investigators have demonstrated that a VSD can be safely closed through an incision of the TV, there is a lack of data regarding

Scanning this QR code will take you to the article title page.

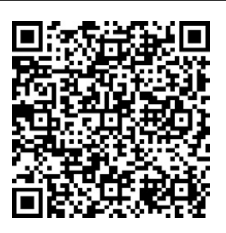




\section{Abbreviations and Acronyms \\ VSD $=$ ventricular septal defect \\ $\mathrm{TV}=$ tricuspid valve \\ $\mathrm{TR}=$ tricuspid regurgitation}

outcomes after VSD closure through the TV incision in young infants, including neonates. This study aimed to investigate patient outcomes after repair of the VSD through a detached TV in infants younger than 3 months.

\section{MATERIALS AND METHODS \\ Patients}

Between January 2004 and December 2013, a total of 1455 patients who had undergone corrective surgery for isolated VSD at Asan Medical Center, Seoul, Korea, were identified from our database. Among these patients, 296 infants younger than 3 months who underwent isolated VSD closure through a right atrial approach were enrolled in this study. Patient medical records were reviewed to obtain echocardiographic findings and surgical details. On the basis of preoperative echocardiographic reports, morphologic data about the defect, including alignment of the outlet septum, aneurysm formation, and chordal attachment of the TV around the margin of the VSD, were obtained. We considered the TV chordal attachment to be abnormal when any TV chordae were traversing the hole of the defect and attached to the anterior or superior margin according to echocardiography. This finding can be obtained through a subcostal coronal view with anterior tilting or an apical 4-chamber view. Operative details, including the use of a TV incision, the site and direction of the incision, the VSD repair technique, and repair of the detached TV, were obtained. The TV was detached for better exposure of the defect in 49 patients ( $16.6 \%$, study group), whereas it was not detached in 247 patients ( $83.4 \%$, control group). The study was approved by the institutional review board of Asan Medical Center (approval IRB No. S2015-1591-0001), and the requirement for informed consent was waived because of the retrospective nature of the analysis.

\section{Operative Technique}

During the study period, patients were operated on by 4 pediatric cardiac surgeons. All procedures were performed under moderate hypothermic cardiopulmonary bypass with intermittent antegrade administration of either cold blood or crystalloid cardioplegic solution. A left heart vent was inserted through the right upper pulmonary vein or interatrial septal defect as appropriate. After aortic crossclamping, the VSD was exposed through the right atriotomy. If the VSD behind the TV was difficult to access, the TV was detached in various sites and directions at the discretion of the surgeon. The TV was detached parallel $(n=42)$ or perpendicular $(n=7)$ to the annulus on the septal leaflet $(n=40)$, anterior leaflet $(n=3)$, or both leaflets $(n=6)$. The VSD was closed with a Dacron polyester fabric patch (BARD Peripheral Vascular, Inc, Tempe, Ariz) or $0.625 \%$ glutaraldehyde-treated autologous pericardium with buttressed 6-0 polypropylene sutures (Woorhi, Inc, Gyeonggi-do, Korea) according to the preference of the surgeon. The detached TV leaflet was repaired with 7-0 or 6-0 polypropylene suture (Ethicon, Inc, Somerville, NJ) in an interrupted or continuous running fashion as appropriate. Cold saline solution was directly injected into the right ventricle to evaluate the competence of the TV. On the basis of the saline injection test result, additional TV procedures, including partial obliteration of the anteroseptal commissure or a Kay-type annuloplasty, were performed to reduce the degree of TR in 54 patients: 8 of $49(16.3 \%)$ in the study group and 46 of 247 $(18.2 \%)$ in the control group $(P=.79)$.

\section{Follow-up Echocardiography}

After closure of the VSD, echocardiography was performed at the time of hospital discharge in all cases, and follow-up echocardiography was generally performed 6 months after the surgery. Subsequent echocardiographic and clinical follow-up evaluations were scheduled at the discretion of the referring cardiologist. The severity of TR was assessed on the basis of echocardiographic findings according to American Society of Echocardiography recommended criteria ${ }^{11}$ as follows: none to trivial, 0 ; mild, 1; mild to moderate, 2; moderate to severe, 3; and severe, 4. Significant TR was defined as greater than grade 2 .

\section{Statistical Analysis}

Categoric variables are presented as frequencies or percentages as appropriate, and intergroup differences in the variables of interest were analyzed with the Fisher exact test. Continuous variables are expressed as medians with ranges, and intergroup differences of the variables of interest were analyzed with the Mann-Whitney test. To identify factors associated with detachment of the TV, the logistic regression model was fitted. All reported $P$ values were 2 -sided. For statistical analyses, SPSS version 12 (IBM Corporation, Armonk, NY) was used.

\section{RESULTS \\ Preoperative Characteristics}

Demographic data for all patients are summarized in Table 1. The median patient age was 63.5 days (range, 14-90 days), and the median weight was $4.4 \mathrm{~kg}$ (range, 2.1-6.7 kg); differences between groups were not detected. Approximately $70 \%$ of patients had been administered preoperative cardiac medications, such as diuretics, digoxin, or enalapril (study group vs control group, $P=.35$ ). Accompanying genetic syndromes were present in 6 patients $(12.2 \%)$ in the study group and in 20 patients $(8.1 \%)$ in the control group; no difference between groups was identified $(P=.58$; Table 1$)$.

Preoperative echocardiographic findings are summarized in Table 2. The type of VSD was perimembranous in 269 patients and muscular in 27 patients; no difference between groups was detected $(P=.28)$. Abnormal chordal attachment or aneurysmal sac formation of the TV was more frequently observed in the study group. The degrees of TR or outlet septum malalignment were not significantly different between groups. Logistic regression analysis identified an abnormally attached chorda of the TV that crossed the defect as a morphologic parameter that indicated the need for detachment of the TV during the operation (odds ratio, 4.265; 95\% confidence interval, $1.791-10.156 ; P=.001$ ), and aneurysm formation of the TV was likely to be associated with detachment of the TV during surgery $(P=.073$; Table 3$)$.

\section{Operative Outcomes}

The cardiopulmonary bypass time $(90.8 \pm 33.3$ vs $73.4 \pm 21.6$ minutes; $P=.001)$ and aortic crossclamp time $(60.0 \pm 22.1$ vs $46.1 \pm 15.2$ minutes; $P<.001)$ were significantly longer in the study group (Table 4). Concomitant TV repair during VSD closure was performed 
TABLE 1. Patient characteristics

\begin{tabular}{lccc}
\hline & $\begin{array}{c}\text { Control } \\
(\mathbf{n}=\mathbf{2 4 7})\end{array}$ & $\begin{array}{c}\text { Study } \\
(\mathbf{n}=\mathbf{4 9})\end{array}$ & $\begin{array}{c}\boldsymbol{P} \\
\text { value }\end{array}$ \\
\hline Age (d; median and range) & $64(14-90)$ & $60(29-89)$ & .91 \\
Male sex & $123(49.8 \%)$ & $26(53.1 \%)$ & .76 \\
Weight (kg; median and range) & $4.4(2.1-6.7)$ & $4.3(2.1-5.7)$ & .39 \\
Cardiac medication & & & .35 \\
Any & $169(68.4 \%)$ & $34(69.4 \%)$ & \\
None & $78(31.6 \%)$ & $15(30.6 \%)$ & \\
Diuretics only & $108(43.7 \%)$ & $18(36.7 \%)$ & \\
Digoxin only & $7(2.8 \%)$ & $2(4.1 \%)$ & \\
Diuretics plus digoxin or enalapril & $50(20.2 \%)$ & $14(28.6 \%)$ & \\
Genetic syndrome & & & .58 \\
Any & $20(8.1 \%)$ & $6(12.2 \%)$ & \\
Down syndrome & $11(4.5 \%)$ & $4(8.2 \%)$ & \\
Other genetic syndrome & $9(3.6 \%)$ & $2(4.1 \%)$ & \\
\hline
\end{tabular}

Data represent number and percentage of patients except as noted.

in 45 patients in the control group $(18.2 \%)$ and in 8 patients in the study group $(16.3 \%)$; the difference between the groups was not statistically significant $(P=.79$; Table 4$)$. One in-hospital death occurred, that of a premature baby with Noonan syndrome in the study group who died because of capillary leak syndrome after neonatal repair (Table 4). The median stays in the intensive care unit and the hospital were 2 days (1-119 days) and 6 days (4-125 days), respectively, and the differences between groups were not significant $(P=.56$ and $P=.83$; Table 4$)$. Postoperative junctional ectopic tachycardia occurred in 5 patients $(1 / 49$ vs $4 / 247 ; P>.99$ ), and heart block that required a permanent pacemaker developed in 2 patients in the control group (Table 4). On predischarge echocardiography, residual VSD could be observed in 74 patients (10/49 vs $64 / 247 ; P=.474)$, and significant TR was detected in 1 patient $(1 / 49$ vs $0 / 247 ; P=.134)$.

TABLE 2. Preoperative echocardiographic findings

\begin{tabular}{lccc}
\hline & $\begin{array}{c}\text { Control } \\
(\mathbf{n}=\mathbf{2 4 7})\end{array}$ & $\begin{array}{c}\text { Study } \\
(\mathbf{n = 4 9 )}\end{array}$ & $\begin{array}{c}\boldsymbol{P} \\
\text { value }\end{array}$ \\
\hline Type of VSD & & & .28 \\
$\quad$ VSD (perimembranous) & $222(89.9 \%)$ & $47(95.9 \%)$ & \\
$\quad$ VSD (muscular) & $25(10.1 \%)$ & $2(4.1 \%)$ & \\
Outlet septum alignment & & & .16 \\
$\quad$ Normal & $153(61.9 \%)$ & $35(71.4 \%)$ & \\
Anteriorly malaligned & $79(32.0 \%)$ & $14(28.6 \%)$ & \\
$\quad$ Posteriorly malaligned & $15(6.1 \%)$ & $0(0.0 \%)$ & \\
Tricuspid regurgitation & & & .43 \\
$\quad$ None & $141(57.1 \%)$ & $28(57.1 \%)$ & \\
Grade 1 & $89(36.0 \%)$ & $15(30.6 \%)$ & \\
Grade 2 & $14(5.7 \%)$ & $4(8.2 \%)$ & \\
$\quad$ Grade 3 or 4 & $3(1.2 \%)$ & $2(4.1 \%)$ & \\
Anomalies of chordal attachment & $17(6.9 \%)$ & $11(22.4 \%)$ & .002 \\
TV aneurysmal sac & $40(16.2 \%)$ & $13(26.5 \%)$ & .06 \\
Normal LV function & $239(96.8 \%)$ & $47(95.9 \%)$ & .67 \\
\hline Data represent number and percentage of patients. VSD, Ventricular septal defect; \\
$T V$ tricuspid valve; $L V$, left ventricle. & & &
\end{tabular}

TABLE 3. Factors associated with detachment of the tricuspid valve

\begin{tabular}{lclc}
\hline \multicolumn{1}{c}{ Variables } & OR & \multicolumn{1}{c}{$\mathbf{9 5} \% \mathbf{C I}$} & $\boldsymbol{P}$ value \\
\hline TV chordal attachment anomalies & 4.265 & $1.791-10.156$ & .001 \\
TV septal aneurysm & 2.050 & $0.936-4.490$ & .073 \\
Body weight & 0.862 & $0.604-1.231$ & .414 \\
Genetic syndrome & 0.938 & $0.306-2.880$ & .912 \\
Preoperative significant TR & 4.081 & $0.641-25.993$ & .137 \\
Anteriorly malaligned outlet septum & 1.139 & $0.547-2.374$ & .728 \\
\hline OR, Odds ratio; $C I$, confidence interval; & $T V$, tricuspid valve; $T R$, tricuspid \\
regurgitation. & & &
\end{tabular}

\section{Follow-up}

The median follow-up durations were 66 months (range, 19-138 months) and 57 months (range, 1-138 months) in the study and control groups, respectively; differences between groups were not significant $(P=.214)$. There were 4 late deaths that were related to an airway problem, such as aspiration pneumonia or laryngomalacia. Among these patients, 3 had some genetic syndrome-Edward, Down, or Turner syndrome. All these late deaths occurred in the control group.

Follow-up echocardiography was available for 282 patients $(282 / 295,95.6 \%)$ at a median of 21 months (range, 1-108 months) after the operation; no difference between groups was detected $(P=.26)$. According to the most recent echocardiography, significant TR was observed in 1 patient in the study group, and VSD leakage existed in 4 patients ( 1 in the study group, 3 in the control group); the differences between groups were not significant (Table 4). Figure 1 shows changes in the distribution of the degree of TR in both groups.

Reoperation for either residual VSD or significant TR was required in 3 patients ( 1 in the study group and 2 in the control group). The characteristics of the patients who

TABLE 4. Operative data and outcomes

\begin{tabular}{lllc}
\hline & $\begin{array}{c}\text { Control } \\
(\mathbf{n}=\mathbf{2 4 7})\end{array}$ & $\begin{array}{c}\text { Study } \\
(\mathbf{n = 4 9 )}\end{array}$ & $\begin{array}{c}\boldsymbol{P} \\
\text { value }\end{array}$ \\
\hline $\begin{array}{l}\text { Operative data } \\
\quad \text { Cardiopulmonary bypass time }\end{array}$ & $73.4 \pm 21.6$ & $90.8 \pm 33.3$ & .001 \\
$\quad($ min; mean \pm SD) & & & \\
$\quad$ Crossclamp time (min; mean \pm SD) & $46.1 \pm 15.2$ & $60.0 \pm 22.1$ & $<.001$ \\
$\quad$ Concomitant TV repair & $45(18.2 \%)$ & $8(16.3 \%)$ & .79 \\
Postoperative outcomes & & & \\
$\quad$ In-hospital death & $1(0.4 \%)$ & $0(0.0 \%)$ & $>.999$ \\
ICU stay (d, median and range) & $2(1-119)$ & $2(1-19)$ & .56 \\
Hospital stay (d, median and range) & $6(4-125)$ & $7(4-29)$ & .83 \\
$\quad$ Junctional ectopic tachycardia & $4(1.6 \%)$ & $1(2.0 \%)$ & $>.999$ \\
PPM implantation & $2(0.8 \%)$ & $0(0 \%)$ & $>.999$ \\
Latest echocardiography (21 mo) & & & .54 \\
$\quad$ Residual VSD & $3(1.3 \%)$ & $1(2 \%)$ & .17 \\
\hline TR greater than grade 2 & $0(0 \%)$ & $1(2 \%)$ &
\end{tabular}

Data represent number and percentage of patients except as noted. $S D$, Standard deviation; $T V$, tricuspid valve; $I C U$, intensive care unit; $P P M$, permanent pacemaker; $V S D$, ventricular septal defect; $T R$, tricuspid regurgitation. 

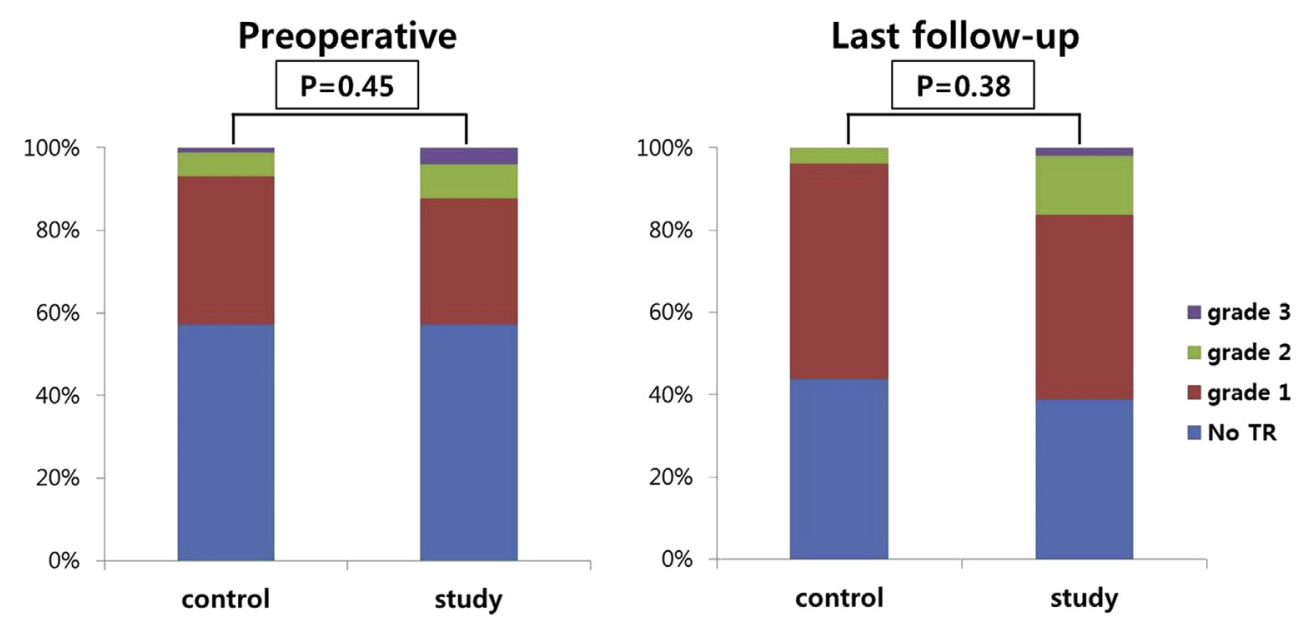

FIGURE 1. Distribution of the degree of tricuspid regurgitation before and after repair. $T R$, Tricuspid regurgitation.

underwent reoperation for residual VSD or significant TR are summarized in Table 5.

\section{DISCUSSION}

VSD represents the most common congenital heart disease $^{12,13}$ and is currently surgically closed with approximately $0 \%$ mortality in cases of an isolated form. As the age at repair decreases and a significant number of babies with ventricular septal defects associated with complex heart disease come to require neonatal repair, the outcome of TV detachment in young infants, including neonates, increasingly merits further study. Adequate exposure of the VSD is crucial for the successful closure of the defect without morbidities, including residual leakage, significant tricuspid insufficiency, and atrioventricular block. If $\mathrm{TV}$ chordal crossing and insertion at the margin of the VSD is present or aneurysmal changes of the septal leaflet of the TV exist, it may be difficult to expose the entire margin of the VSD without inducing excessive traction on the TV leaflet or VSD, which is a major cause of morbidity after VSD closure. To avoid these complications, many studies have suggested the utility of detaching the $\mathrm{TV}^{4-10}$ or even detaching the papillary muscle ${ }^{14}$ for better exposure of the defect in some patients.

Since its initial introduction by Hudspeth and colleagues $^{15}$ in 1962, various incisions of the TV have

TABLE 5. Characteristics of 3 patients who underwent reoperation

\begin{tabular}{lcclllc}
\hline & & & & $\begin{array}{c}\text { Genetic } \\
\text { syndrome }\end{array}$ & $\begin{array}{c}\text { Cause of } \\
\text { reoperation }\end{array}$ & Interval (d) \\
\hline 1 & 85 & 5.1 & Study & Down & LV-RA shunt & 64 \\
2 & 70 & 4.4 & Control & Down & LV-RA shunt & 47 \\
3 & 41 & 3.9 & Control & NA & LV-RA shunt & 21 \\
\hline
\end{tabular}

$B W$, Body weight; $L V$, left ventricle; $R A$, right atrium; $N A$, not applicable. been used by many investigators to improve visualization of the VSD margin with satisfactory outcomes. Gaynor and coworkers ${ }^{4}$ demonstrated that detachment of the TV can safely and effectively improve visualization of the VSD without increasing the risk of a heart block or TR. They made an incision that was parallel to the annulus of the TV and could be repaired with continuous or interrupted sutures as appropriate. Similar techniques and outcomes have been reported by others. ${ }^{5,6,8,9}$ Russell and associates ${ }^{10}$ noted a good midterm outcome of residual VSD or significant TR with a radial incision of the TV to expose the margin of VSDs, which was first described in 1992. ${ }^{16}$ They closed the TV with interrupted sutures in all cases. Tatebe and colleagues ${ }^{17}$ emphasized the avoidance of a running suture when repairing a detached TV after VSD closure because of the development of late significant TR. We mainly used a TV incision parallel to the annulus, although a radial incision was also sometimes used according to the intraoperative morphology. Repair of the incised TV also varied (continuous or interrupted) at the surgeon's discretion. Nevertheless, the outcome was satisfactory with a single tiny residual leak and a single case of asymptomatic moderate TR on most recent echocardiography irrespective of the incision or repair techniques.

In this study, 3 reoperations ( 1 in the study group, 2 in the control group) were required because of residual leakage within a rather short interval $(21,47$, and 64 days, respectively), and the shunt was placed from the left ventricle to the right atrium at the VSD stitch, which was anchored at the TV annulus (Table 5). The leakage thus may have been a technical problem and not related to the visualization itself.

One reason that surgeons hesitate to detach the TV during VSD closure is that this procedure requires additional time for incising and repairing the TV. In our study, the 
cardiopulmonary bypass time and aortic crossclamp time were significantly longer in the study group, as expected. Because the morphology of the defect was more likely to be unfavorable for exposure in the study group, however, a simple comparison of the time between the 2 groups might be unfair. ${ }^{8}$ The longer cardiopulmonary bypass and crossclamp times also may not have been clinically significant, because the stays in the intensive care unit and hospital were similar between the groups.

In addition, if we can predict the probability of TV detachment during VSD closure before entering the operating theater, we can reduce the time required by eliminating the time spent trying to expose the margin. ${ }^{8}$ Sasson and colleagues ${ }^{9}$ described 3 criteria that they used to identify patients who could potentially benefit from TV detachment to facilitate VSD closure in their study: (1) multiple TV chordal arrangement obscuring the margins of the defect; (2) TV aneurysm that precludes easy access to the defect; and (3) a high position of the defect with outlet extension that requires excessive traction on the TV leaflet for exposure. In our study, some preoperative echocardiographic findings may have been related to the high probability of TV incision during VSD surgery. Abnormally attachment of any chordae of the TV crossing the defect was identified as a morphologic parameter that indicated the need for detachment of the TV during the operation. In addition, aneurysm formation of the TV was likely to be associated with detachment of the TV during surgery. These findings, however, do not necessarily mean that detachment of the TV should always be recommended for patients with abnormal chordal attachment or aneurysm of the TV. Rather, it can be inferred that prompt detachment of the TV is recommended when conventional approaches for VSD are not adequate to expose the defect in patients with the aforementioned preoperative morphologic features.

Despite its rare occurrence, ${ }^{2}$ one of the most serious complications after closure of the VSD is complete atrioventricular block. Direct needle injury or unintentional excessive tension on the margin of the defect near the conduction axis is one possible cause of complete heart block. The risk of heart block may increase when any difficulty in exposure of the margin occurs. In our study, permanent pacemakers were required in 2 patients in the control group. Although the intergroup differences were not statistically significant because of the small number of patients, detachment of the TV during VSD closure should be considered to be safe on the basis of the conduction axis from our data in this study.

Although contemporary surgical outcomes of isolated VSD are excellent, with extremely low mortality and morbidity, ${ }^{18}$ age and weight remain significant factors related to patient outcomes, including length of stay and in some respects morbidity. ${ }^{19}$ Nevertheless, there are small infants who require surgical intervention for VSD, irrespective of any association with complex heart disease; there may be difficulty with exposure of the defect in some of these infants because of TV chordal entanglement or septal aneurysm obstructing the exact margin of the defect. We hope that our study will provide useful information for repairing such VSDs in young infants, despite the rather small number of patients and limited duration of follow-up, and we hope that this limitation may be overcome with ongoing and future investigations.

\section{Limitations of This Study}

This study is a retrospective review of patients from a single center with a nonrandomized design. Unknown confounding factors, procedure bias, or selection bias thus may have influenced the results. Although our number of subjects was sizable compared with previous studies of detachment of $\mathrm{TV}$, the number of patients who received concomitant detachment of the TV during closure of the VSD was still relatively small.

\section{CONCLUSIONS}

Detachment of the TV can be used safely to expose the VSD without increasing the risk of TR in young infants. Preoperative echocardiography may be useful for predicting the possibility of detaching the TV to enhance exposure of the VSD.

\section{Conflict of Interest Statement}

Authors have nothing to disclose with regard to commercial support.

\section{References}

1. Jacobs JP, Burke RP, Quintessenza JA, Mavroudis C. Congenital Heart Surgery Nomenclature and Database Project: ventricular septal defect. Ann Thorac Surg. 2000;69(4 Suppl):S25-35.

2. Andersen HØ, de Leval MR, Tsang VT, Elliott MJ, Anderson RH, Cook AC. Is complete heart block after surgical closure of ventricular septum defects still an issue? Ann Thorac Surg. 2006;82:948-57.

3. Dodge-Khatami A, Knirsch W, Tomaske M, Prêtre R, Bettex D, Rousson V, et al. Spontaneous closure of small residual ventricular septal defects after surgical repair. Ann Thorac Surg. 2007;83:902-5.

4. Gaynor JW, O’Brien JE Jr, Rychik J, Sanchez GR, DeCampli WM, Spray TL. Outcome following tricuspid valve detachment for ventricular septal defects closure. Eur J Cardiothorac Surg. 2001;19:279-82.

5. Bol-Raap G, Weerheim J, Kappetein AP, Witsenburg M, Bogers AJ. Follow-up after surgical closure of congenital ventricular septal defect. Eur J Cardiothorac Surg. 2003;24:511-5

6. Zhao J, Li J, Wei X, Zhao B, Sun W. Tricuspid valve detachment in closure of congenital ventricular septal defect. Tex Heart Inst J. 2003;30:38-41.

7. Maile S, Kadner A, Turina MI, Prêtre R. Detachment of the anterior leaflet of the tricuspid valve to expose perimembranous ventricular septal defects. Ann Thorac Surg. 2003;75:944-6.

8. Aeba R, Katogi T, Hashizume K, Koizumi K, Iino Y, Mori M, et al. Liberal use of tricuspid valve detachment for transatrial ventricular septal defect closure. Ann Thorac Surg. 2003;76:1073-7.

9. Sasson L, Katz MG, Ezri T, Tamir A, Herman A, Bove EL, et al. Indications for tricuspid valve detachment in closure of ventricular septal defect in children. Ann Thorac Surg. 2006;82:958-63; discussion 963. 
10. Russell HM, Forsberg K, Backer CL, Wurlitzer KC, Kaushal S, Mavroudis C. Outcomes of radial incision of the tricuspid valve for ventricular septal defect closure. Ann Thorac Surg. 2011;92:685-90; discussion 690.

11. Zoghbi WA, Enriquez-Sarano M, Foster E, Grayburn PA, Kraft CD, Levine RA, et al. Recommendations for evaluation of the severity of native valvular regurgitation with two-dimensional and Doppler echocardiography. J Am Soc Echocardiogr. 2003; 16:777-802.

12. Hoffman JI, Kaplan S, Liberthson RR. Prevalence of congenital heart disease. Am Heart J. 2004; 147:425-39.

13. Hoffman JI, Kaplan S. The incidence of congenital heart disease. J Am Coll Cardiol. 2002;39:1890-900.

14. Kapoor L, Gan MD, Bandyhopadhyay A, Das MB, Chatterjee S. Improved exposure of isolated perimembranous ventricular septal defects. Ann Thorac Surg. 2000;69:291-2.

15. Hudspeth AS, Cordell AR, Meredith JH, Johnston FR. An improved transatrial approach to the closure of ventricular septal defects. J Thorac Cardiovasc Surg. 1962;43:157-65.
16. Idriss FS, Muster AJ, Paul MH, Backer CL, Mavroudis C. Ventricular septal defect with tricuspid pouch with and without transposition: anatomic and surgical considerations. J Thorac Cardiovasc Surg. 1992;103:52-9.

17. Tatebe S, Miyamura H, Watanabe H, Sugawara M, Eguchi S. Closure of isolated ventricular septal defect with detachment of the tricuspid valve. J Card Surg. 1995;10:564-8.

18. Scully BB, Morales DL, Zafar F, McKenzie ED, Fraser CD Jr, Heinle JS. Current expectations for surgical repair of isolated ventricular septal defects. Ann Thorac Surg. 2010;89:544-9; discussion 550-1.

19. Anderson BR, Stevens KN, Nicolson SC, Gruber SB, Spray TL, Wernovsky G, et al. Contemporary outcomes of surgical ventricular septal defect closure. J Thorac Cardiovasc Surg. 2013;145:641-7.

Key Words: ventricular septal defect, tricuspid valve detachment, outcome, infant

\title{
EDITORIAL COMMENTARY
}

\section{Taking 1 step backward to go 2 forward? Managing the tricuspid valve in the surgical closure of a ventricular septal defect}

\author{
S. Adil Husain, MD
}

\footnotetext{
From the Division of Pediatric and Congenital Cardiothoracic Surgery, University of Texas Health Sciences Center, San Antonio, Tex.

Disclosures: Author has nothing to disclose with regard to commercial support.

Received for publication April 10, 2016; accepted for publication April 12, 2016.

Address for reprints: S. Adil Husain, MD, Division of Pediatric and Congenital Cardiothoracic Surgery,

University of Texas Health Sciences Center, San Antonio, TX (E-mail: husain@uthscsa.edu).

J Thorac Cardiovasc Surg 2016;152:496-7

$0022-5223 / \$ 36.00$

Copyright (c) 2016 by The American Association for Thoracic Surgery

http://dx.doi.org/10.1016/j.jtcvs.2016.04.032
}

The era of surgical intervention for ventricular septal defects (VSDs) began in 1952 when Muller and Dammann placed a pulmonary artery band to limit pulmonary blood flow. ${ }^{1}$ Transatrial closure was described subsequently by Stirling et al in $1957 .^{2}$ The use of tricuspid valve (TV) detachment strategies to allow for improved exposure during transatrial closure of a VSD was introduced by Hudspeth in 1962 and has been historically well described. ${ }^{3}$ Surgical literature has focused on technical variations for valve detachment and in turn, provided data consistent with excellent outcomes, regardless of approach. $^{4-6}$

Timing for VSD closure generally has been accepted to occur at 4-6 months of age, with the employment of pharmacologic afterload reduction and diuretic therapies allowing for growth and maturation before surgical intervention. The concept of earlier complete

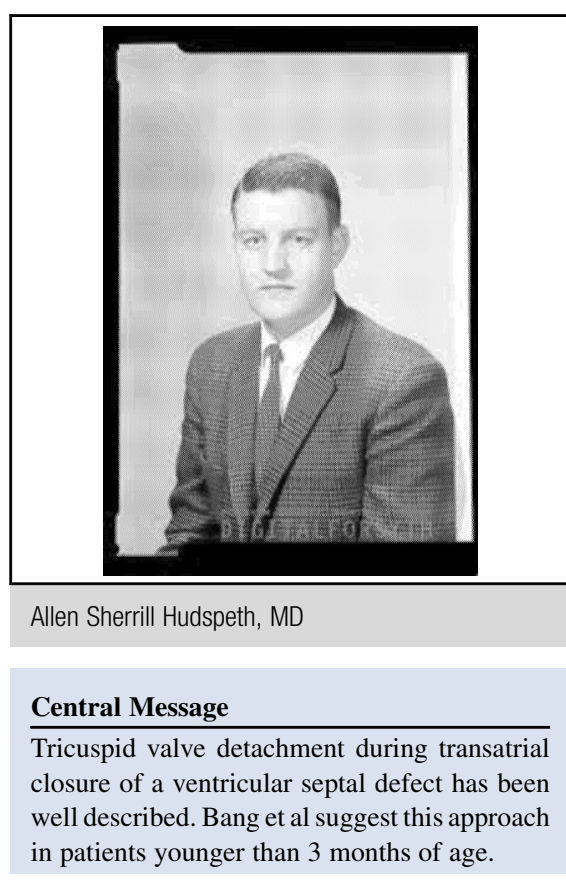

See Article page 491. 